\title{
Improving wheat as a source of dietary fibre for human health
}

\author{
P. R. Shewry ${ }^{1,2}$, S. Reynolds ${ }^{1,2}$, T. Pellny ${ }^{1}$, J. Freeman ${ }^{1}$, M. Wilkinson ${ }^{1}$, O. Kosik ${ }^{1}$, M. Ulker ${ }^{3}$, \\ L. Wingen ${ }^{4}$, S. Orford ${ }^{4}$, S. Griffiths ${ }^{4}$, R. A. C. Mitchell ${ }^{1}$ and A. Lovegrove ${ }^{1}$ \\ ${ }^{1}$ Rothamsted Research, Harpenden, Herts, AL5 2JQ, UK, ${ }^{2}$ University of Reading, Reading RG6 6AR, UK, \\ ${ }^{3}$ Yuzuncu Yil University, Van, Turkey and ${ }^{4}$ John Innes Centre, Norwich, NR4 7UH, UK
}

Wheat is a major source of dietary fibre (DF) in the UK diet, with bread alone providing $20 \%$ of the total daily intake in adults ${ }^{(1)}$. Furthermore, although white bread contains less DF (2.5-4.5\%) than wholemeal (10-14\%), the high consumption (about $65 \%$ of total bread products) means that it alone contributes $11 \%$ of the total intake of $\mathrm{DF}^{(1)}$. The major DF components in white flour and bread are cell wall polysaccharides, principally arabinoxylan (AX) and $\beta$-glucan which account for about $70 \%$ and $20 \%$ of the total, respectively.

Analyses of 150 wheat cultivars grown on the same site showed that the total content of AX in white flour ranged from $1.35 \%$ to $2.75 \%$ dry wt, and of soluble AX from $0 \cdot 30 \%$ to $1 \cdot 40 \%{ }^{(2)}$. The proportion of soluble AX was generally about $25 \%$ of the total. However, the Chinese cultivar Yumai 34 was shown to contain the highest contents of both total and soluble AX, and is now being exploited by wheat breeders as a source of these traits.

We have now analysed wheat lines of wider genetic diversity, including a core set of lines from the Watkins collection of land races which were collected from 32 European, Asian and North African Countries in the 1920s and 1930s ${ }^{(3)}$. Preliminary analyses showed that the range of content of total AX in wholemeal was wider than in the 150 cultivars, with up to $35 \%$ soluble AX (Figure 1 ). This high solubility may be related to differences in the fine structure of AX, particularly the ratio of xylose residues which are substituted with single and two arabinose residues: this is being compared by fingerprinting the patterns of oligosaccharides released after digestion with endoxylanase.

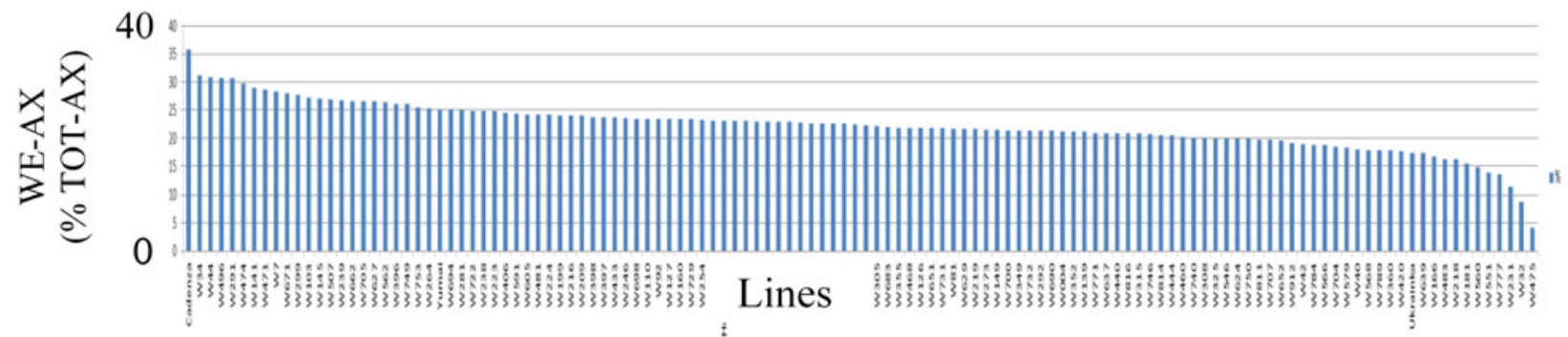

Fig. 1. Content of water-extractable AX (WE-AX) (expressed as \% age of total AX) in wholemeal flours of Watkins lines. AX was determined as pentose units ${ }^{(4)}$.

The lines will be used to improve the DF content and composition of bread wheat. They will also allow us to explore the relationship between the structure and properties of AX and its contribution to human health, including viscosity and prebioitic effects in the colon.

Research at Rothamsted is funded by the Biotechnology and Biological Sciences Research Council (BBSRC) of the UK.

1. Steer T, Thane C, Stephen A \& Jebb S (2008) Proc Nutr Soc 67 (OCE8), E363.

2. Gebruers K, Dornez E, Bedő Z et al. (2010) J Agric Food Chem 58, 9353-9361.

3. Miller TE, Ambrose M \& Reader SM (1999) In: Wheat Taxonomy: the Legacy of John Percival. Caligari PDS \& Brandham PE (Eds.).Academic Press, pp. 113-120.

4. Douglas SG (1981) Food Chem 7, 139-145. 